\title{
2020 Vision: Genetic Counselors as Acknowledged Leaders in Integrating Genetics and Genomics into Healthcare
}

\author{
Jehannine Austin ${ }^{1}$
}

Published online: 19 November 2015

(C) National Society of Genetic Counselors, Inc. 2015

My relationship with NSGC began back in 2002, when I was a student at the University of British Columbia. I was drawn to NSGC because of a true and deep belief in what we do, and getting involved seemed to be a way to advocate for ourselves and for our patients on a bigger scale. The people I saw involved in the leadership of NSGC were people who I found inspiring and saw as role models. When I paid my first NSGC (and Psychiatric SIG) membership dues, I remember feeling that I did not have anything meaningful to contribute, but I wanted to interact with and learn from the inspiring people I saw being involved so that - eventually I could contribute too. So, taking on the role that you have entrusted me with - becoming President of our organization, is a huge and deeply meaningful honor to me. It is a privilege and responsibility, and it is something I take very seriously - especially because you have for the first time in NSGC's history, entrusted this role to a non-American. I promise not to let you down.

In preparing to take on this role, I have been thinking about where we are currently at as an organization, and about where we want to be - I have been thinking about exactly what we are striving to achieve as an organization, what my role is in that, what I see as being the challenges that we face, and what we can all do to help move us forward. As I was thinking about this, I came across a

Jehannine Austin

Jehannine.austin@ubc.ca

1 UBC Department of Psychiatry and Medical Genetics, CFRI Translational Lab Building, 938 W28th Ave, Vancouver, BC V5Z 4H4, Canada quote from Marshall Ganz, about leadership. He says that leadership is about:

"... accepting responsibility for enabling others to achieve shared purpose in the face of uncertainty."

This quote does not just talk about my role as president, the "shared purpose" concept also describes what I see as our collective role as an organization, and the "in the face of uncertainty" part accurately describes the environment we operate within. But, I'd like to talk with you about the "shared purpose" first.

My experience has revealed that sharing (which, to me, implies connecting) and purpose are deeply important - both lead to feelings of satisfaction. And satisfaction is a key issue for us. For years, the Professional Status Survey (PSS) has shown that overall, genetic counselors love their jobs. But, satisfaction consistently emerges as the area that receives the lowest ratings on the survey.

I propose that we can collectively achieve deeper levels of professional satisfaction by consciously working towards a meaningful shared purpose together. Beyond my own experience, there is even some evidence to support this; the PSS shows that the more professional activities members are engaged in, the more satisfied they are. Sure, as a researcher, I have to acknowledge that there are other ways of interpreting these data, but I like the interpretation I shared with you best!

\section{Defining our Shared Purpose}

Our shared purpose as an organization must involve realizing our vision and achieving our mission:

Vision: Integrating genetics and genomics to improve health for all. 
Mission: to advance the various roles of genetic counselors in health care by fostering education, research, and public policy to ensure the availability of quality genetic services.

I interpret these statements to mean that genetic counselors will be acknowledged as leaders of the integration of genetics and genomics into healthcare. I am convinced that our recent discussions about the clinical doctorate were only superficially about whether we want or need more training, it was really about wanting more autonomy, respect, room for growth, that we are not satisfied with being handmaidens to the integration of genetics and genomics into healthcare. We want to be acknowledged as leaders. Achieving this vision is what I see as being our shared purpose, and I am committed to working hard to connect with all of you so that we can realize it together.

But, as we work towards this, it is important to acknowledge that we are facing uncertainty.

\section{What is the Uncertainty that we Face?}

We are facing uncertainty about what our roles might be as the future unfolds. With or without the leadership of genetic counselors, genetics and genomics will be integrated into healthcare - it is already happening - across all areas of medicine. In her 2013 leadership award address Wendy Uhlmann acknowledged this - she talked about how thegenetics and genomics train has already left the station, and implored us to step up to drive the train, instead of being passengers on it. A Will Rogers quote comes to mind:

\section{"Even if you're on the right track you'll get run over if you just sit there."}

There is no doubt that we are on the right track, as evidenced by the fact that the rest of medicine is now catching up to us! And although we are certainly not "just sitting there", we are still at risk of being run over. For example, I have heard arguments that because there are "too few genetic counselors", in order to meet the increasing clinical need for people skilled in the application and interpretation of genetics and genomics, we should be investing in training molecular pathologists. My take on this is that if we are to invest in training additional service providers, we should be investing in training larger numbers of genetic counselors.

You might be thinking that it does not matter whether we lead this integration, what matters is that it happens. But, if we do not lead it, and instead work to empower other healthcare providers to deliver our services, our profession could become (as Bob Resta put it) "an evolutionary dead end".

You might then suggest that if genetics and genomics are integrated in such a way as to promote better health for all, perhaps the extinction of the genetic counseling profession would not really a problem to anyone other than us. To that, I say absolutely and unquestionably, that allowing the extinction of our profession would be a profound disservice to the patients, and future potential patients who stand to benefit from our unique skillset and perspective. To improve health for all to the fullest possible potential, genetic counselors must be integrated into healthcare. We must integrate ourselves throughout all specialties and disciplines, and - though of course it is important to help our colleagues from other professions to integrate genomics into their work - our integration needs to be not just for the short-term purposes of training our colleagues to replace us.

To be clear, I an not suggesting that we need to be directly involved with every single patient, but we have skills and qualities that are unique in healthcare and that make an important difference to patients, and that are not easily replaced.

\section{Our Unique Value}

So, what is our unique value? We bring important value to healthcare; reducing costs by ensuring appropriate tests are ordered, and we pride ourselves on interpreting genetic tests more accurately than many others can. But as tests become cheaper and more generic (e.g. whole genome sequencing), and results come from the lab accompanied by interpretation, what is the role for genetic counselors in the clinical setting? Of course, we provide good information about the role of genetics in health conditions. But print material, websites, and other healthcare professionals can also provide good information.

So where does that leave us? What is our unique value? To me, it's clear. What we do is - should be - about more than just providing information. What makes us unique is our blend of genetics expertise and counseling skills, and our foundational belief in the importance of patient autonomy and it is this that cannot easily be outsourced to other healthcare providers. No matter whether we provide clinical services, or work in research roles, lab-based or industry positions it is this unique blend of skills and qualities that makes us valuable. 
Advocating for patients' best interests is fundamental to our profession even for those of us who are not involved in direct patient care. We have a responsibility to advocate for ourselves, to claim our rightful place as recognized leaders of the integration of genetics and genomics into healthcare - not for our own aggrandizement, but out of responsibility to the patients and future patients that we are uniquely placed to help.

\section{A Roadmap to Claiming our Place as Recognized Leaders in the Integration of Genetics and Genomics into Healthcare}

Claiming our place as recognized leaders in the integration of genetics and genomics in healthcare is not necessarily going to be easy. But, I know that we can do it. It is not something that can be achieved by any one person alone. But, by working together we can do it. So, I ask you to engage with me, with each other, your professional community, and with your organization - for us all to work together towards this shared purpose.

As I ask for this, I am coming from a place of deep appreciation and respect for all of you, knowing that you all give a lot already, that you are busy. I am acutely aware that I have the incredible privilege of addressing an extraordinarily engaged membership. But despite knowing, and deeply appreciating this, I am still asking you - each and every one of you - to engage, and to give more. I ask you for this for two reasons. First, because the right kind of doing more - working towards a shared and meaningful purpose - will pay out personal dividends in terms of fulfillment and professional satisfaction to us all as individuals. Second, because is it our responsibility to our patients that we claim our rightful place as acknowledged leaders of the integration of genetics and genomics into healthcare, and that will take all of us working together. There are six specific things that I am asking for us to do, all of which will benefit our profession through the advancement of us each as individuals (see Table 1).

Table 1 A roadmap to claiming our place as recognized leaders in the integration of genetics and genomics into healthcare

Recognize our power to influence our own destiny as a profession

Conquer imposter syndrome

Nurture assertiveness

Find your own meaning

Build our community (communicate/celebrate)

Act with optimism

\section{Recognize our Power to Influence our Own Destiny as a Profession}

Many of us have a tendency to think that if we just do a good job we will be rewarded for it - others will notice and we will eventually be asked to lead the integration of genetics and genomics into healthcare. Unfortunately, doing our jobs well is not enough. To drive the genetics and genomics train we must take and own the power that we have - we must take the controls - rather than waiting for them to be given to us. As Gloria Steinem put it:

Power can be taken, but not given.

We value and promote our patients' autonomy, we empower them, helping them choose their preferred healthcare options. But ironically, not all of us feel autonomous and empowered ourselves. For those among us feeling this way, some words from Alice Walker:

"The most common way people give up their power is by thinking they don't have any."

So, the first thing I ask for us all to do, is that we consciously acknowledge that we do have the power to influence our destiny as a profession, and work towards taking it. The remaining items in my list are strategies for wielding our power to influence our professional destiny.

\section{Conquer Imposter Syndrome}

Imposter syndrome leads a person to feel convinced that they are a fraud, that they do not deserve the success they have achieved. It involves dismissing evidence of competence (like awards or accomplishments) as luck, or others inexplicably thinking you are more intelligent or competent than you really are, and it can act as an obstacle to fulfilling ones potential. When I first learned about imposter syndrome, I recognized it in myself immediately, and from my interactions with many fabulous, accomplished genetic counselors over the years, I am convinced that a substantial proportion of you have imposter syndrome too. The first step to overcoming it so that you can reach your full potential is recognizing it.

A source of my own imposter syndrome is the fact that I have experienced depression, which for a long time, I thought meant that I could not truly be competent. I was ashamed, felt it was a sign of weakness, and I was convinced that if people knew this, they would think less of me. Though I wanted to contribute meaningfully at a leadership level, I felt that I could not. I ultimately realized that my experience with depression 
could actually be considered a leadership credential - and I share this insight for any of you for whom the topic of depression resonates (statistically, that would be at least a couple of hundred of you). Specifically, leadership (which is about inspiring and enabling others) requires positivity and optimism, often in the face of high personal costs as a result of tough decisions that leaders are responsible for making, that affect them emotionally.

Now, you'd be forgiven for thinking that an experience with depression is not a great training ground for developing positivity and optimism! But, if you have had to make a conscious decision to keep going with whatever hope, faith, or determination you can muster although there really does seem to be no way out of a suffering that is unbearable, and to have made it, and found it worthwhile - then that gives one a certain confidence in ones strength. Even in situations where there is no immediate solution to a large problem, having come through depression, I can feel optimistic that I'll find a way through the situation at hand, even if I do not know how yet. This is useful preparation for leadership.

I share my imposter syndrome story to challenge you all to consider if your own version of it could be holding you back, and, if it is, to find ways to overcome it - it helps with nurturing assertiveness.

\section{Nurture Assertiveness}

There is a social tendency to think of assertiveness in women who make up the bulk of our profession - as being incompatible with being likable, and to mislabel it as aggressiveness. While aggressiveness is about attack, assertiveness is about putting oneself forward; making oneself noticed - without it being at the expense of others. Assertiveness portrays confidence and competence, and brings opportunities for increased autonomy, respect and responsibility. Assertiveness is about being forthright about expressing your rights, wants and needs -even when you know you will not necessarily get what you seek. Assertiveness skills can be learned, and can be as simple as challenging yourself to develop a solid handshake, sit at the table at meetings with more senior colleagues, and stop using opening phrases like "I am not the expert but..." or "I am not sure but...". For those who have mastered these skills, contribute your thoughts and ideas more often at meetings, or make the commitment to mentor a more junior colleague in developing their assertiveness skills.

\section{Find your Own Meaning}

We may not feel that we have the luxury of time to reflect and identify what it is that we do that gives us the deepest sense of purpose and meaning as individuals. But, as an organization, our ability to achieve our shared purpose is, in part, a result of individual members realizing their own unique purpose.
When individuals achieve their own purpose, the outcome for their organization is greater than the sum of the parts. For this reason, I ask all of us to consciously consider what it is we do that we find to be most meaningful, and to focus our efforts and energies in that direction. If we are clear about our purpose, and we are consciously working towards achieving it in a manner that aligns with our values, we can find ourselves liking who we are, what we do and how we do it - and that is what Maya Angelou describes as success, she said:

\section{"Success is liking who you are, liking what you do and liking how you do it."}

To me, what Maya Angelou describes as success sounds a lot like feeling satisfied - and as we have discussed, that is something in which we - as a profession - have a deficit. But, if we can find our purpose and work towards it, it can create energy and inspiration that benefits us personally, those around us, and through a ripple effect, the broader community.

\section{Build our Community}

Though NSGC has a phenomenally engaged membership, I would like to grow that even more - I'd like you to work with me to build our community. There are two strategies in particular that I'd like to invite you to use to do this: communication and celebration.

Communication is challenging when an organization is growing, and as one of 3000 members, it can be easy to feel distanced, and to have questions about how decisions get made, and for trust to falter. I have had the privilege of witnessing that the leadership you have chosen acts with consistent integrity, and always for the best interest of members. But not everyone will have the opportunity to participate in a board of directors meeting to experience this first hand. So, I commit to continuing to work to find ways to communicate effectively within our organization, to building trust and engagement, but I am asking you to connect with me - and the whole board, too. Communicate with us directly - let us know about the issues that are important to you, ask us about decisions we made, and through this connection we can build trust and community.

Another important part of community building is to celebrate each other's successes. Sometimes, the success of others can be seen as a threat, or we can use it to measure what we see as our own inferiority. But, there is only a very fine line between feeling jealous and feeling inspired - both arise from admiring something in someone else. So I challenge us to reframe any negative energy we may feel when a colleague stands out in their success - to make the tiny tweak such that instead of feeling threatened, we feel inspired. When one genetic counselor succeeds, we all - collectively - succeed. When one of us wins - we all win. As our colleagues reach 
new heights, break new ground, push back boundaries, as we observe an increasing scope for what is possible, a ripple effect can be created. I have been inspired to action by the professional successes that I have seen of those around me. So as another way to build community and momentum, I ask that we celebrate each other's professional successes of all kinds within your SIGs, committees, and local geographic areas, and to let board members know so that we can share news about and celebrate your successes too. But lets do more than that lets nominate our colleagues for awards - not just within our own organization, but within our institutions and areas, lets create those opportunities to celebrate.

\section{Act with Optimism}

Becoming recognized as leaders in the integration of genetics and genomics into healthcare might feel like a huge task. We might feel paralyzed by its enormity. When I feel this way, it helps to break the task down into smaller pieces and think of another quote, this one by Edmund Burke:

"No-one makes a greater mistake than he who does nothing because he could only do a little."

So, the last thing I ask of us all is that we face our future as a profession with optimism, with the belief that we can do this. In practice, this might be reflected in how we speak to each other about things. For example, when first I mentioned my desire to get involved with NSGC years ago, I remember hearing things like: "Well, you can try, but its an old girls' network...." Later, when I mentioned that I had put my name in the hat to stand for President, I heard: "Good luck, but they'd never accept a Canadian as president...." Given where I am today, clearly these messages were wrong, and clearly they did not stop me, but they did sap a little of my energy. Energy is a precious resource that we cannot afford to squander. I challenge us all to become conscious of our negative thoughts and words, and fight them by encouraging and inspiring each other, by supporting each other in the belief that we have the power to influence our profession's destiny.

\section{"Small Acts, when Multiplied by Millions of People can Transform the World" - Howard Zinn}

Genetic counselors are uniquely valuable, and we have a responsibility to our patients and our future patients to advocate for ourselves and to claim our place as leaders in the integration of genetics and genomics into healthcare. These things that I suggest we can all do may each seem relatively small, but if 3000 people - the members of NSGC - recognize our power, conquer imposter syndrome, nurture assertiveness, find our own meaning, build our community, and act with optimism, we can produce a cultural shift in our profession that changes the scope of what is possible for us all as individuals and as an organization.

I will do my part in the coming year. Though I am taking on the title of president of our organization, that does not necessarily make me a leader. I have to earn that descriptor by inspiring and enabling you, and by earning your trust though my actions. I commit to working hard in the coming year to do exactly this. In taking on this role, I am consciously “...accepting responsibility for enabling others to achieve shared purpose in the face of uncertainty" - and I invite you all to work with me, so that together we can move towards achieving our shared purpose as a profession and realizing our vision - of becoming the recognized leaders of the integration of genetics and genomics into healthcare. 